\title{
pH Reduction of Cement Paste Using Supercritical $\mathrm{CO}_{2}$
}

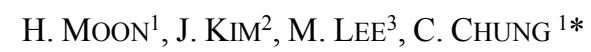

${ }^{1}$ Dept. of Architectural Engineering, Pukyong National University, Busan 48513, South Korea

(mhmoona@naver.com,

*correspondence: cwchung@pknu.ac.kr)

${ }^{2}$ Multidisciplinary Infra-technology Research Laboratory,

Pukyong National University, Busan 48513, South Korea

(kjh@pknu.ac.kr)

${ }^{3}$ Dept. of Earth Environmental Sciences, Pukyong National

University, Busan 48513, South Korea

(heelee@pknu.ac.kr)

Recently, due to the depletion of natural aggregates, it is recommended to use recycled aggregates produced by recycling waste concrete. Most of the recycled aggregates are used for landfill. However, due to environmental problems caused by strong alkaline leachate from circulating aggregates, it is difficult to be actively used. The strong alkalinity of recycled aggregates is due to the $\mathrm{Ca}(\mathrm{OH})_{2}$ present in the cement mortar attached to the surface of the recycled aggregates. The supercritical $\mathrm{CO}_{2}\left(\mathrm{scCO}_{2}\right)$ has the properties of both gas and liquid[1], so it is believed that the alkalinity of the circulating aggregate can be sufficiently reduced by penetrating into the inside of the circulating aggregate and reacting with $\mathrm{Ca}(\mathrm{OH})_{2}$. In this study, to observe the carbonation reaction between cement components and $\mathrm{scCO}_{2}$, cement paste powder (less than $0.15 \mathrm{~mm}$ ) and deionized water were used to react with $\mathrm{scCO}_{2}$. Reaction conditions were three types of temperature $\left(50{ }^{\circ} \mathrm{C}, 65^{\circ} \mathrm{C}, 80^{\circ} \mathrm{C}\right)$, and three types of pressure (100 bar, $150 \mathrm{bar}, 200 \mathrm{bar}$ ), and reaction time was 24 hours. The $\mathrm{pH}$ of the cement paste before the reaction with $\mathrm{scCO}_{2}$ was 12.5 , but the $\mathrm{pH}$ of the cement paste after the reaction was lowered from 10.12 to 8.7 depending on the temperature and pressure conditions. Although the $\mathrm{pH}$ of the cement paste that did not react with $\mathrm{scCO}_{2}$ did not change significantly with time, the sample reacted with the $\mathrm{scCO}_{2}$ showed a continuous decrease in $\mathrm{pH}$ as the days passed. On the 7th day of measurement, the $\mathrm{pH}$ of the cement paste was lowered up to 8.33 depending on the temperature and pressure conditions. According to the experimental results, when $\mathrm{scCO}_{2}$ reacts with recycled aggregates, the cement mortar on the surface of recycled aggregates can be carbonated to reduce the $\mathrm{pH}$ and be used as a landfill material.

[1] Gupta et al. (2013) Nuclear Engineering and Design 261, 116-131. 